and non-human conflict. Collins rightly stresses that confrontations seldom progress beyond threat and bluster, and he is right to ask why. His answer is, at best, shallowly descriptive: "No matter how motivated someone may be, if the situation does not unfold so that confrontational tension/fear is overcome, violence will not proceed." Factors that allegedly facilitate overcoming this "tension/fear" are the expressions, postures and behaviour of the other party, numerical or technical advantage and the support of an audience.

Again, much of this is not news. Threat displays, bluffing and audience effects on violence all have literatures of their own. It is 35 years since John Maynard Smith and George R. Price provided, in these pages (Nature 246, 15-18; 1973), a game theoretical analysis of why threat displays are common and damaging violence is rare. Posturing conveys information about both fighting ability and the individual-specific value of winning a contest. Violence is "hard" because it endangers the perpetrator as well as his target.

Sociologists often defend the autonomy and importance of their discipline by disparaging 'psychologizing.' To his credit, Collins realizes that phenomena such as emotions are essential components of a satisfactory explanation of human behaviour. Yet, perhaps to retain his sociological 'cred', he eschews consideration of current knowledge in psychology, physiology and neuroscience. He ignores a vast body of emotion research with direct implications for his theory, and much highly relevant work on the relative importance of situational versus individual attributes in the variability of behaviour. Moreover, Collins resurrects the notion that motivation is a sort of 'energy' that can be dammed up only to spill over into irrelevant activities, without acknowledging the devastating critiques by Robert Hinde and others that led to the rejection of such Freudian/Lorenzian models in the 1960s. Collins's goal of characterizing the micro-dynamics of social interaction is laudable, but he is blinkered by disciplinary parochialism.

Does Collins really have the 'theory' his subtitle promises? If so, it is not one from which any testable hypotheses flow - theory here seems closer to its meaning in the humanities than in the sciences. Reading the book in this spirit, one finds keen observations and persuasive interpretations of aspects of police violence, domestic abuse, gang fights and the behaviour of men at war. But the road to a scientific understanding of violence is interdisciplinary. Margo Wilson and Martin Daly are professors in the Department of Psychology, Neuroscience and Behaviour at McMaster University, 1280 Main Street West, Hamilton, Ontario, Canada L8S 4K1. They are co-authors of Homicide and The Truth about Cinderella.

\title{
The invisible revolution
}

\section{Nanosciences: La Révolution Invisible By Christian Joachim and Laurence Plévert Seuil: 2008. 182 pp. Can\$31.95, €18 (in French)}

\section{Vincent Dusastre}

Nanotechnology was originally defined in the 1970 s as the science of manipulating atoms and single molecules. Its remit has since expanded to embrace all technologies capable of building structures at the scale of a billionth of a metre. How and why did this change happen and has it affected the field's development?

Politics and big business caused the shift, according to physicist Christian Joachim and journalist Laurence Plévert. In their Frenchlanguage book they argue convincingly that this more inclusive definition has also altered the initial goals of nanotechnology research.

Richard Feynman's 1959 lecture, 'There's Plenty of Room at the Bottom', touched on the difficulties of controlling matter at the atomic scale. But the term nanotechnology was first coined by Norio Taniguchi, at Tokyo Science University, in 1974. This was about the same time that Ari Aviram and Mark Ratner, at IBM, proposed the idea of a single-molecule rectifier.

In the early 1980s, the invention of the scanning tunnelling microscope, which could image and manipulate single atoms, made it possible to design nanoscale machines from individual atoms and molecules. Joachim, who worked as a young researcher at IBM at that time, takes us on a nostalgic personal journey from single molecules to today's molecular machines, such as organic molecules capable of moving and performing calculations. Given the visual interest of the tiny machines, it is a

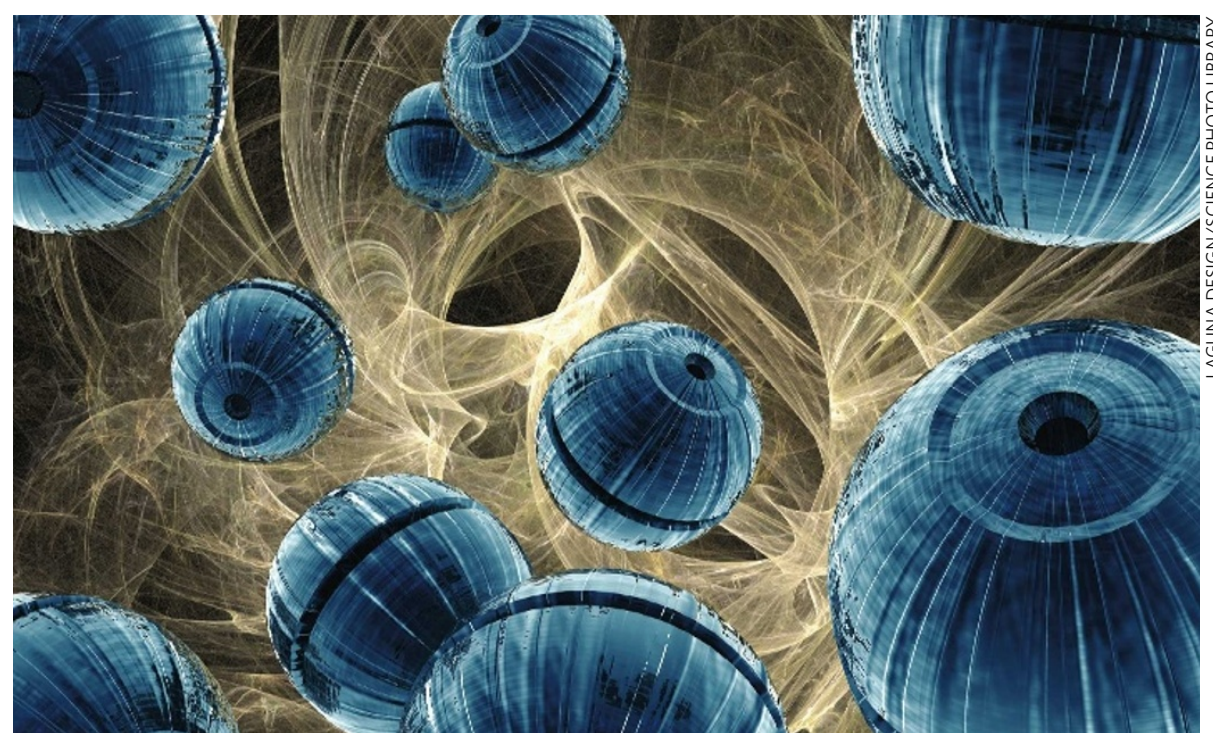

Molecular-scale machines could one day have medical applications such as removing cancerous cells.

pity that his gripping story is not illustrated.

Until the 1990s atomic manipulations were developed with sustainability in mind. Hope was that building machines from the bottom up, atom by atom, rather than top down, etching them from larger blocks, would minimize the energy and materials expended in manufacturing. US industrial lobbies then broadened the definition as a way of accessing public funds earmarked for materials and chemistry research and development. These lobbies convinced the Clinton administration to launch the National Nanotechnology Initiative in 1999, which fostered energy-intensive topdown techniques for fabricating and sculpting objects less than a micrometre in size.

The initiative's generous funding boosted industrial development and innovation in globally competitive areas such as microelectronics and biotechnology. For fear of being left behind, funding agencies worldwide, including in Europe and Japan, quickly adopted similarly broad definitions. More recently, nanotechnology has ventured even further. It is now portrayed as a key and novel way of tackling the world energy crisis and water shortage. Yet top-down production is intrinsically wasteful of materials and energy.

The drive to miniaturize has been with us a long time. Joachim and Plévert chart the progression from ancient Greek astrological clocks to James Watt's steam engine to the discovery of the electron and finally today's microelectronics. The authors explain clearly that, when 


\section{EXHIBITION \\ Essence of creation}

\author{
Isabelle Kaufmann \\ Both biotechnologists and artists \\ create. Genesis - The Art of \\ Creation, at the Zentrum Paul Klee \\ in Bern, Switzerland, suggests \\ their methods and aesthetics show \\ unexpected kinships. \\ The Zentrum Paul Klee houses \\ the largest collection of works by \\ the eponymous early-twentieth- \\ century painter, who spent much \\ of his life in Bern. Working at the \\ interface of figurative and abstract \\ art, Klee studied the forms of \\ plants, shells and stones, and drew \\ from them new and imaginative \\ shapes. \\ Genesis - the process of creation \\ - was a key theme. According \\ to Klee, the painter starts with \\ the basic elements of point, \\ line, tone and colour (pictured, \\ physiognomische Genesis, 1929). \\ He experimented with them, \\ recombining them, and so bringing \\ something new into existence. \\ Replace brush and canvas with \\ pipette and test tube, and this, the \\ exhibition posits, could be a genetic \\ engineer rearranging DNA and \\ creating new forms of life. \\ Klee's geometric compositions \\ and chimaeric beasts are \\ juxtaposed with paintings by
}

fellow modernists such as Piet Mondrian and anatomical drawings by Leonardo da Vinci. Exhibits by contemporary artists borrow the techniques of biotechnology. A video of transgenic organisms in Eduardo Kac's installation projects a plate of bacteria expressing blue or yellow fluorescent proteins; as the cells grow, mutate and conjugate, new colour variations emerge.

Also on display are paintings and prints inspired by microscopic images. Ross Bleckner's In Replication imagines the scene inside a dividing cell: a wild and colourful dance of molecules pairing, entwining and separating. David Fried's bubble shapes recall pictures of fertilized egg cells, captured in reproduction, and growing in harmonic patterns. These pieces demonstrate that scientific images enrich our knowledge and that their unusual beauty has a truth of its own. Isabelle Kaufmann is a researcher at the Sir William Dunn School of Pathology, University of Oxford, South Parks Rd, Oxford OX13RE, UK.

Genesis - The Art of Creation (until 27 April) is at the Zentrum Paul Klee, Bern, Switzerland (www.zpk.org).

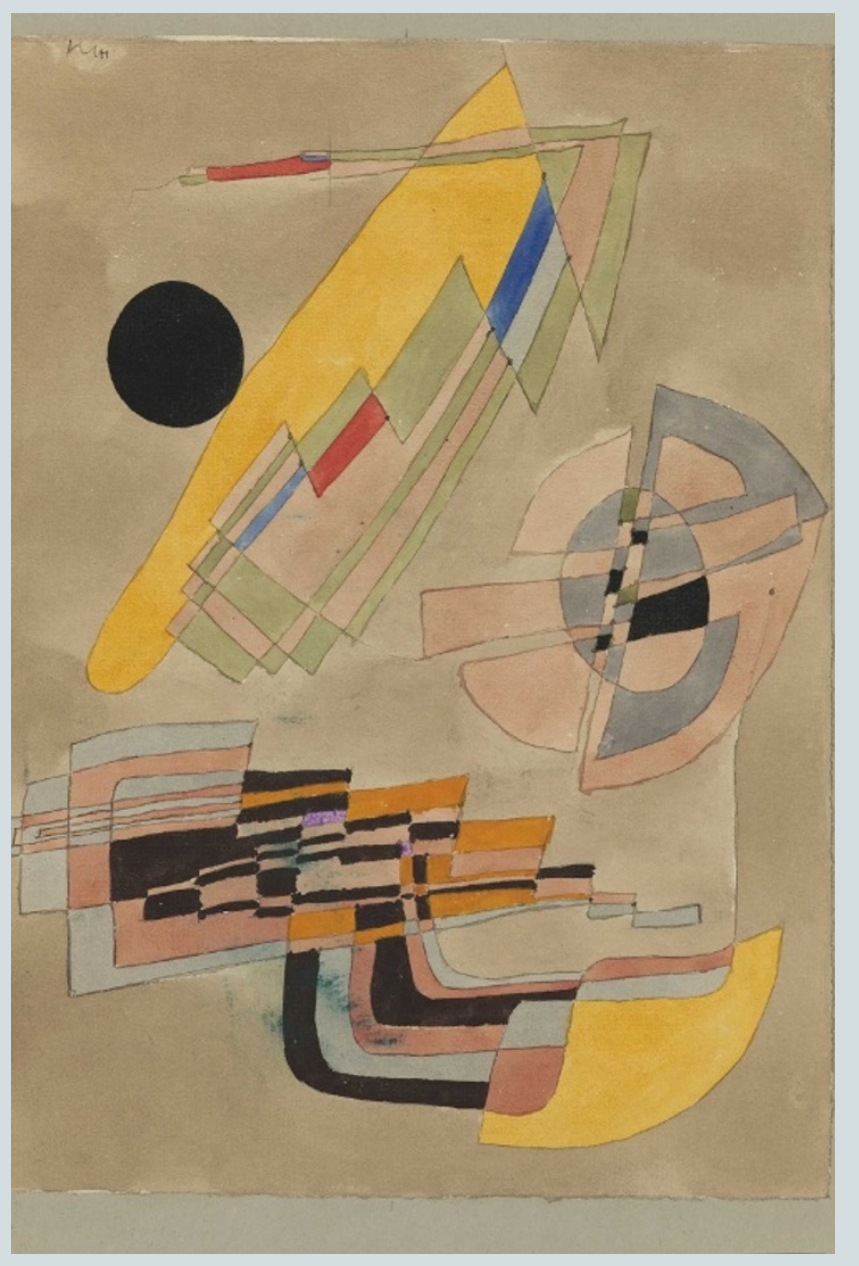

applied to integrated electronics and electromechanical systems, lithographic techniques are reaching a physical limit. Moreover, below a scale of tens of nanometres, fundamental problems such as interconnection and quantum effects arise.

Today, nanotechnology is embracing biology. The authors rightly dismiss fantastic worries that our DNA may be modified by nanobots capable of getting into cells as well as nanotechnology's dubious association with genetically modified organisms. But they are rash to focus on recent controversial observations of bacteria less than 100 nanometres long that might be incorporated into molecular machines. They ought instead to have emphasized current research efforts to build machines from selfassembly and supramolecular chemistry.

Caveats aside, this popular book sets out the science that underpins nanotechnology and in so doing gives a realistic picture of its impact, applications and political, economic and societal context.

Vincent Dusastre is editor of Nature Materials (www.nature.com/naturematerials).

\section{Genomes evolve, but how?}

\section{The Origins of Genome Architecture \\ By Michael Lynch \\ Sinauer: 2007.510 pp. \$59.95 (hbk)}

\section{Axel Meyer}

"Nothing in biology makes sense, except in the light of evolution," said the great geneticist and evolutionary biologist Theodosius Dobzhansky. Twenty-five years on, genomics as a discipline has yet to embrace evolution fully. Michael Lynch is an exception. His timely textbook demands that population thinking, population genetics and evolutionary theory be meshed more explicitly. After all, genomes did not appear suddenly from nowhere, and mutational changes from single base-pair substitutions to whole-genome duplications are at least one basis of molecular as well as phenotypic evolutionary change.

As the cost of genome-sequencing falls and more genomes of the major model systems are sequenced, evolutionary biologists have more say in which organisms will be investigated next. Population samples of, for example, the model species Drosophila (fruitflies) are a good target.

Yet this line of research is still driven strongly by technical innovation, such as the speed and cost of data collection, rather than the testing of theories that might direct future experiments. Genomics research is progressing incredibly fast, off the back of genomic data that are being produced ever more rapidly. Still in a stage of wondrous discovery, this nascent field today evokes the excitement of the early days of natural history.

Lynch is a population geneticist who has made major contributions to numerous evolutionary questions and recently expanded his interests to genomics. He has published landmark studies on mutation rates, gene 